\title{
OS NOVOS SANITARISTAS NO MUNDO DO TRABALHO: UM ESTUDO COM GRADUADOS EM SAÚDE COLETIVA
}

\author{
THE NEW SANITARY WORKERS IN THE WORLD OF LABOR: \\ A STUDY AMONG COLLECTIVE HEALTH GRADUATES
}

LOS NUEVOS HIGIENISTAS EN EL MUNDO DEL TRABAJO: UN ESTUDIO CON GRADUADOS EN SALUD PÚBLICA

Jussara Lisboa Viana ${ }^{1}$

Elizabethe Cristina Fagundes de Souza ${ }^{2}$

Resumo Discorreremos sobre a inserção profissional dos bacharéis em Saúde Coletiva, especificamente quanto aos desafios, potencialidades e estratégias de inserção no mundo do trabalho. A produção dos dados ocorreu, principalmente, por três sessões de grupo focal com os egressos dos anos de 2012.2, 2013.2 e 2014.2, da graduação de Saúde Coletiva da Universidade Federal do Rio Grande do Norte. Os relatos extraídos foram sistematizados e submetidos à técnica de análise de conteúdo temática de Bardin. Sobre os desafios profissionais, debatemos as subcategorias: remuneração, reconhecimento da profissão em Saúde Coletiva, interferência política, e identidade. Já as potencialidades têm as seguintes subcategorias: vivências práticas durante a formação; núcleo de saber e prática da Saúde Coletiva; e cenário da Secretaria Municipal de Saúde de Natal. Quanto às estratégias para inserção profissional, identificamos ações de caráter individual e coletivo, um movimento organizado por egressos e estudantes, que visam divulgar o curso e seu profissional, bem como avançar no processo de construção de uma nova profissão.

Palavras-chave saúde coletiva; mercado de trabalho; graduação em saúde coletiva.
Abstract We discuss the professional integration of Collective Health graduates, particularly regarding the challenges, the potentialities and the strategies of integration in the world of labor. The production of data occurred mainly by means of three focal group sessions with the graduates from the classes of 2012.2, 2013.2 and 2014.2 of the undergraduate course on Collective Health of the Federal University of Rio Grande do Norte (Universidade Federal do Rio Grande do Norte, in Portuguese). The resulting accounts were systematized and subjected to Bardin's thematic content analysis technique. Regarding the professional challenges, we discuss the subcategories: salary, recognition of the Collective Health profession, political interference, and identity. As for the potentialities, they have the following subcategories: practical experiences during the undergraduate studies; a center for knowledge and practice in Collective Health; and the circumstances within the Municipal Health Department of the state capital of Natal. Regarding the strategies for professional integration, we identified actions of an individual as well as collective nature, a movement organized by graduates and students, who aim to divulge the course and its professional, as well as to make progress in the process of construction of a new profession.

Keywords collective health; job market; undergraduate studies in collective health. 


\section{Introdução}

Os Cursos de Graduação em Saúde Coletiva (CGSC) surgem do imaginário criativo de representantes do Movimento Sanitário ao compreenderem que a formação graduada atenderia a um anseio social de profissionais qualificados em Saúde Coletiva para atuar, principalmente, no Sistema Único de Saúde (SUS). A proposta formativa torna-se viável por um contexto político de incentivo e ampliação do acesso ao ensino superior, especialmente de segmentos populacionais historicamente desfavorecidos desse ensino. O Programa de Apoio a Planos de Reestruturação e Expansão das Universidades Federais (Reuni), do Ministério da Educação (MEC), decreto n. 6.096/2007 (Brasil, 2007), marca a história da Saúde Coletiva ao apoiar a criação de novos cursos de graduação e, por sua característica democrática e inclusiva, traz para esses cursos a pluralidade e diversidade no perfil socioeconômico dos estudantes, peculiaridades que se refletem na identidade dos novos sanitaristas.

Consideramos que, em período histórico passado, outros sujeitos construíram caminhos que hoje também são percorridos pelos bacharéis em Saúde Coletiva. Lembremo-nos dos sanitaristas graduados em Medicina do início do século XX que se apropriaram do conhecimento da Higiene em suas atividades profissionais de prevenção e controle das doenças infectocontagiosas e epidêmicas nas grandes cidades e em zonas rurais vinculadas ao comércio (Merhy, 1992; Amaral, 2006).

Os modelos tecnoassistenciais das ações coletivas de saúde - denominados por Merhy (1992) - e as correntes de pensamento desenvolvidas internacionalmente subsidiaram a prática dos sanitaristas brasileiros. Assim, algumas denominações sobre essa prática foram criadas nesse período histórico como, por exemplo, modelo campanhista, movimento permanente especializado, rede local permanente e movimento desenvolvimentista.

Os movimentos de Reforma Sanitária Brasileira (RSB) impulsionaram mudanças no sistema de saúde, ao mesmo tempo em que a organização desse sistema provocou novas formas de pensar o campo, como saberes, práticas e política. A RSB, na década de 1970, debatia a saúde em seu conceito ampliado e como direito, incorporado na Constituição Federal de 1988.

A criação do SUS fez os debatedores do campo da Saúde Coletiva identificarem a necessidade de profissionais qualificados para impulsionar as mudanças não alcançadas na última RSB. Alguns apontaram como estratégia o fortalecimento desses saberes e práticas nas diversas graduações da área da saúde (Koifman e Gomes, 2008). Outros defendiam a criação de um novo profissional advindos de uma formação de nível superior (Paim e Pinto, 2013; Belisário et al., 2013). 
A criação desse novo profissional e aquela necessidade de fortalecer as graduações não são ideias antagônicas. Esses posicionamentos se complementam ao compreendermos que esse campo precisa estar presente na produção da saúde e, portanto, na prática dos demais profissionais desta área, e que há, também, um núcleo da Saúde Coletiva demarcando um conhecimento específico e especializado que poderá sustentar uma nova profissão.

Nessa perspectiva, os sanitaristas graduados aparecem para suprir a demanda no mundo do trabalho por profissionais capacitados para atuar no planejamento, gestão e execução de ações em Saúde Coletiva (Koifman e Gomes, 2008); e com a amplitude e complexidade do setor atuariam na perspectiva da promoção da saúde e seriam orientados por uma concepção interdisciplinar (Ruela, 2013). Dessa forma, espera-se que esses bacharéis sejam novos sujeitos políticos (Associação Brasileira de Saúde Coletiva, 2012a).

Houve um longo processo de discussão para a criação desses cursos, Santos (2014) destaca que os principais espaços de debate pós-anos 2000 foram: em 2002, a oficina de Trabalho "Graduação em Saúde Coletiva: pertinência e possibilidades", realizada pelo Instituto de Saúde Coletiva da Universidade Federal da Bahia; em 2003, o V Congresso Nacional da Rede Unida em Londrina; em 2005, o Fórum Social Mundial em Porto Alegre; em 2003, o VII Congresso Brasileiro de Saúde Coletiva, Brasília; e em 2008, a Reunião em Belo Horizonte e a Reunião em Salvador. Em alguns desses eventos estiveram presentes entidades de classe, estudantes, professores, gestores e outros coletivos sociais.

Em 2001, com a criação da Universidade Estadual do Rio Grande do Sul, surge, segundo Ceccim (2002), o primeiro Curso de Graduação do campo da Saúde Coletiva denominado de Administração de Sistemas e Serviços de Saúde. ${ }^{3}$ Em 2008, por sua vez, há uma expansão dos CGSC no Brasil e, atualmente, estão presentes nos estados do Acre, Amazonas, Pará, Bahia, Pernambuco, Rio Grande do Norte, Distrito Federal, Mato Grosso, Rio de Janeiro, São Paulo, Minas Gerais, Paraná e Rio Grande do Sul.

Sobre os cursos, destacamos que há uma diversidade de nomenclaturas, carga horária e estrutura curricular. Alguns apresentam ênfase em Gestão em Saúde Coletiva Indígena, Gestão em Sistemas e Serviços de Saúde e Gestão em Saúde Ambiental (Meneses et al., 2017), e que no dia 10 de agosto de 2017 as Diretrizes Curriculares Nacionais (DCNs) do CGSC, discutidas no âmbito do Fórum de Graduação em Saúde Coletiva (FGSC) da Associação Brasileira de Saúde Coletiva (Abrasco), foram aprovadas pelo Conselho Nacional de Educação (Brasil, 2017a). As DCNs desdobram-se nos seguintes núcleos de conhecimentos e práticas: Gestão em Saúde; Atenção à Saúde; e Educação e Comunicação em Saúde. 
No primeiro semestre de 2014, havia um total de 2.532 estudantes com matrículas ativas nos 18 CGSC em funcionamento no Brasil e 285 egressos. A Universidade de Brasília (campus Ceilândia) e a Universidade Federal do Rio Grande do Norte (UFRN) foram as que mais contribuíram com esse número (Meneses et al., 2017).

Especificamente na UFRN, entre os anos de 2008 e 2009, foi criado o Curso de Graduação em Gestão em Sistemas e Serviços de Saúde (GSSS) na modalidade bacharelado. O conjunto de conteúdos e práticas que compõem o projeto pedagógico caracteriza-o como pertencente à Saúde Coletiva e, desse modo, esse curso ocupa espaços de representação nacional dos CGSC do Brasil. Informamos que os processos de mudança de nomenclatura do Curso de GSSS para Saúde Coletiva e de estrutura curricular seguem em tramitação.

Em 2012, alguns dos bacharéis em Saúde Coletiva do Brasil relataram, na V Reunião do FGSC da Abrasco (2012b), que os profissionais, quando os receberam nos espaços de trabalho, desconheciam esse novo sanitarista e seus espaços de atuação, e que alguns estados pareciam mais favoráveis à inserção profissional, enquanto outros demostraram contextos limitadores. Esses bacharéis já sabiam que a construção de identidade e de reconhecimento profissional seria feita no trabalho na relação produzida com outros atores da saúde.

Na sequência, exploraremos o processo de inserção dos bacharéis em Saúde Coletiva no mundo do trabalho, tendo como lócus o cenário do Rio Grande do Norte, para buscarmos responder como se dá a inserção (espaço, tempo, condicionantes) desses profissionais, mais especificamente na identificação e no debate sobre desafios, potencialidades e estratégias de inserção profissional.

\section{Reflexividade na pesquisa e trajetória metodológica}

Ao designarmos os bacharéis de Saúde Coletiva como novos sanitaristas, estamos considerando a constituição de novos sujeitos-agentes ético-políticos da Saúde Coletiva, inspirados em Paim e Pinto (2013), que compreendem que esses novos sujeitos realizam práticas para além do sanitarismo e rompem com a Saúde Pública institucionalizada.

Além disso, nosso posicionamento é definir a Saúde Coletiva como dois espaços de saberes e de práticas, o campo e o núcleo. No primeiro, há o ato compartilhado por profissionais de diferentes áreas que o usam como apoio para suas formações de origem e, no segundo, ocorre a delimitação da identidade do profissional sanitarista. É nessa perspectiva que se pretendeu a construção conceitual metodológica deste estudo baseada em Campos (2000).

$\mathrm{O}$ estudo ${ }^{4}$ se vincula às noções de implicação e reflexividade na pesquisa, na medida em que as pesquisadoras estão diretamente implicadas, uma na condição de egressa e outra na condição de docente do curso analisado. Nes- 
sa relação, Merhy (2004) destaca que o pesquisador ao interrogar o sentido das situações em foco, interroga a si mesmo e a sua própria significação como sujeito desse processo. Hammersley e Atkinson (1994) dizem que a reflexividade traz a interação, o posicionamento, a implicação do sujeito com o objeto estudado; e as autoras Minayo e Guerreiro (2014) enfatizam a necessidade de o pesquisador externar sua posição no texto.

Para selecionar os participantes do estudo, enviamos aos 84 egressos dos anos de 2012.2, 2013.2 e 2014.2 um questionário do FormSUS no qual identificamos os que haviam trabalhado ou não na área de formação e os que aceitaram participar da pesquisa através de sessão de grupo focal (GF). Daqueles, 50 egressos responderam ao questionário e, entre estes, 37 aceitaram participar da pesquisa, dos quais 16 egressos, com diferentes perfis (trabalham na área de formação; trabalham, mas não na área; e não trabalham), participaram de três sessões de GF. As três sessões foram suficientes para explorar o debate sobre inserção profissional na perspectiva de entrevista grupal.

Além disso, sete egressos foram entrevistados individualmente (entrevista com roteiro semiestruturado) e alguns desses também haviam participado das sessões de GF. No total, 21 egressos participaram do estudo, em grupos focais e entrevistas individuais. Para assegurar o anonimato dos entrevistados, seus nomes foram substituídos por letras do alfabeto.

A técnica de GF foi adotada por considerarmos que estimularia a interação entre os participantes do grupo ao privilegiar a discussão grupal. Assim, a interação possibilitou disparar novas ideias sobre a inserção dos bacharéis no mundo do trabalho, como também estimulou opiniões divergentes (Souza, 2017).

As sessões dos GF foram norteadas em seu planejamento e desenvolvimento pela abordagem sistematizada por Souza (2017), que destaca algumas estratégias, como por exemplo: a escolha da equipe de pesquisadores (moderador e relatores) e local de realização; os roteiros norteadores da discussão; a comunicação com os participantes, por meio de convite à sessão e lembrete prévio da data dos GF; a gravação dos áudios de cada sessão; e o lanche ao final de cada sessão para os participantes.

As sessões de GF e as entrevistas individuais foram gravadas e, em seguida, transcritas. Os relatos extraídos foram sistematizados e analisados pela técnica de análise de conteúdo temática, que, segundo Bardin (2004), organiza-se em três fases: a pré-análise; a exploração do material; e o tratamento dos resultados, inferência e interpretação.

Além da análise temática desse material para identificar as categorias e as subcategorias que foram base para apresentação e discussão dos resultados, recorremos também à descrição narrativa de depoimentos extraídos durante as entrevistas, considerando a riqueza dos relatos individuais quanto às experiências dos egressos. 
Deixamos clara a limitação desta pesquisa ao reconhecermos a ausência de outras vozes de sujeitos envolvidos no mundo do trabalho, já que nosso estudo se limitou à escuta dos egressos do curso de GSSS da UFRN. Nesse aspecto, sugerimos novas pesquisas que conversem com outros atores dos sistemas de saúde para que tenhamos melhor compreensão desse novo sanitarista no mundo do trabalho.

$\mathrm{O}$ estudo foi realizado com base nos princípios éticos e o projeto foi submetido e aprovado em 16 de novembro de 2015 pelo Comitê de Ética em Pesquisa do Hospital Onofre Lopes da UFRN, sob o registro CAAE n. 49972815.20000.5292.

\section{Sobre inserção dos bacharéis no mundo do trabalho}

Os resultados e discussões estão agrupados nestas seguintes categorias: desafios e dificuldades, potencialidades e estratégias de inserção profissional. Salientamos que os desafios e as potencialidades de inserção são de caráter contextual e temporal, e as estratégias se colocam como ações e movimentos que tentam superar os desafios existentes e ampliar a empregabilidade dos novos sanitaristas.

\section{Desafios para a inserção profissional}

Ao abordar esta categoria de análise, temos de considerar o contexto estrutural de desafios do mundo do trabalho; dessa forma, Mendes (2016) destaca algumas reformas legislativas que podem interferir nos direitos sociais trabalhistas, como:

a aprovação da lei n. 13.135/2015, que altera regras para prejudicar o acesso à pensão por morte e auxílio-doença ao trabalhador; b) a aprovação da lei $\mathrm{n}$. 13.134/2015, que muda as regras para dificultar o acesso ao seguro-desemprego e ao abono salarial; a aprovação da lei n. 13.183/2015, que dispõe sobre a nova regra mais restrita referente ao cálculo das aposentadorias; a permissão à entrada do capital estrangeiro na saúde, por meio da aprovação da lei n. 13.097/2015; a aprovação da EC 86/2015, que consolida o subfinanciamento histórico do SUS; a manutenção da Desvinculação da Receita da União por 21 anos (Mendes, 2016, p. 15-16).

E ainda acrescentamos: a lei n. 13.429/2017, que dispõe sobre o Trabalho Terceirizado irrestrito (Brasil, 2017b); h) a lei n. 13.467/2017, que altera a Consolidação das Leis do Trabalho (CLT) e permite que os acordos entre patrões e empregados sejam superiores ao legislado (Brasil, 2017c). 
Além disso, Mendes (2016), seguindo a corrente marxista, destaca que os direitos trabalhistas e a Seguridade Social (Saúde, Previdência e Assistência Social) sofrem impactos do capitalismo contemporâneo pelo processo de 'financeirização' (capital portador de juros). ${ }^{5}$

No nosso estudo, identificamos que as subcategorias de desafios não são isoladas entre si e que algumas se relacionam, são elas: remuneração; reconhecimento da profissão em Saúde Coletiva; interferência política; e identidade profissional.

Alguns egressos apontaram como desafio à inserção profissional a baixa remuneração para algumas ocupações na área de formação. Em um estudo sobre os egressos do CGSC da Universidade Federal da Bahia, foi identificado salário médio de R\$2.607 (Anjos, 2015). Em outro estudo incluindo diversos egressos do Brasil, foi identificado que 29,6\% ganham mais de R $\$ 3.391$, $49,2 \%$ disseram ganhar entre R\$ 1.357 e R\$ 3.390 e outros $21,3 \%$ recebem entre $\mathrm{R} \$ 678$ e R\$ 1.356 (Lorena et al., 2016).

Em nossa pesquisa, identificamos duas visões diferentes dos egressos sobre o tema, uma parte dos egressos encara os baixos salários como dificuldade inicial, mas os aceita como uma oportunidade de trabalhar na área de formação. A outra parte recusa este tipo de trabalho e aguarda outras oportunidades mais bem remuneradas na área ou entende que apenas outras ocupações ou outras profissões podem satisfazê-lo financeiramente, como exemplificado na fala do Egresso A, a seguir:

Fui convidado a trabalhar na secretaria de saúde, na época o valor era um salário mínimo para trabalhar 40 horas (...) para mim na época foi frustrante (...) aí eu optei por ir para esse outro emprego, que é enfermeiro da Estratégia [Saúde da Família] (Depoimento de Egresso A).

Entendemos que os egressos que aceitam oportunidade de trabalhar na área de formação conseguem se estabelecer no mundo do trabalho quando comparados com aqueles que apenas aguardam uma oportunidade bem remunerada. Ter experiência profissional revelou ser um facilitador para buscar novos empregos com melhores condições de trabalho. No entanto, a remuneração aparece como um problema estrutural relacionado ao mundo do trabalho em que profissões com maior status social tendem a ter remunerações melhores quando comparadas a outras.

No que diz respeito à subcategoria Reconhecimento da Profissão em Saúde Coletiva, entendemos ser importante refletir como os órgãos do Estado consideram o trabalho e o trabalhador da Saúde Coletiva. Para tanto, recorremos ao registro da Classificação Brasileira de Ocupações (CBO) do Ministério do Trabalho (MTB) e aos processos de regulamentação da profissão no Congres- 
so Nacional e, paralelamente a isso, ressaltaremos os conceitos de ocupação e profissão.

Ocupação é um conceito sintético que representa a agregação de empregos ou situações de trabalho similares. A ocupação é regulamentada pelo MTB que utiliza a CBO. A CBO é um documento normalizador do reconhecimento, da nomeação e da codificação dos títulos e conteúdo das ocupações do mercado de trabalho brasileiro. Ela é constantemente atualizada para expor as diversas atividades profissionais, as regulamentadas e as de livre exercício profissional (Brasil, 2017d).

Destacamos a mobilização nacional de egressos e professores dos diversos CGSC com o apoio do Ministério da Saúde (MS) para a inclusão da ocupação do sanitarista na $\mathrm{CBO}$ do $\mathrm{MTB}$, o registro foi formalizado em 17 de março de 2017, em que bacharéis e pós-graduados na área de Saúde Coletiva/Saúde Pública podem exercer essa ocupação.

Sobre a ocupação de sanitarista (1312-25), são listadas 130 atividades profissionais e está registrada como pertencente à família ocupacional "Gestores e especialistas de operações em empresas, secretarias e unidades de serviços de saúde", família que agrega outras ocupações, quais sejam: diretor de serviços de saúde (1312-05), gerente de serviços de saúde (1312-10), tecnólogo em gestão hospitalar (1312-15) e gerontólogo (1312-20) (Brasil, 2017d).

O MTB também reconhece as diversidades de uma ocupação no campo da Saúde Coletiva por categoria profissional, quais sejam: cirurgião-dentista (2232-72); cirurgião-dentista epidemiologista (2232-16); fonoaudiólogo em Saúde Coletiva (2238-40); pesquisador em Saúde Coletiva (2033-20); enfermeiro sanitarista (2235-60); médico sanitarista (2251-39); e farmacêutico em Saúde Pública (2234-30) (Brasil, 2017d). Identificamos que todas, com exceção de pesquisador em Saúde Coletiva (2251-39), apresentam atividades profissionais semelhantes às atividades descritas pelo MTB para suas formações generalistas de origem.

Com essa breve descrição da CBO, identificamos que alguns conhecimentos desse campo estão presentes na atuação de outras ocupações e que há um saber predominante da Saúde Coletiva nas ocupações de sanitarista e naquelas relacionadas à gestão dos serviços de saúde. Compreendemos que a ocupação de sanitarista representa melhor as atividades profissionais dos bacharéis estudados, reforçando a especialidade e especificidade do trabalho dessa nova ocupação, essas atividades descritas poderão influenciar nas atividades propostas para uma nova profissão.

No tocante à profissão, este é um tipo específico de trabalho especializado, sendo considerado também um tipo especial de ocupação por se tratar de um trabalho reconhecido oficialmente. A profissão necessita de especialização 
criteriosa teoricamente fundamentada, com a capacidade de negociar limites jurisdicionais e controlar sua própria divisão de trabalho. O controle ocupacional do próprio mercado é denominado de "reserva de mercado de trabalho". Essa reserva estabelece que apenas os que possuem credencial, geralmente diploma, podem desempenhar a profissão. Normalmente, as universidades são os espaços de qualificação profissional em que o corpo docente tem dedicação integral para refinar, revisar, codificar o corpo de conhecimentos e qualificações, assim como criar novos elementos (Freidson, 1996).

Sobre a credencial explicitada por Freidson (1996) como necessária à profissão, percebemos uma construção histórica em que no início do século XX o conhecimento da Saúde Coletiva ou correlata da época, segundo Labra (1985), estava presente na formação médica e que, nesse período, alguns debatedores problematizaram que a formação graduada de médicos era insuficiente para a prática de um sanitarista. Posteriormente, em 1925, surge a formação pós-graduada lato sensu para os médicos como necessária para essa atuação.

A partir dos anos 1960 surgem cursos de pós-graduação lato sensu de Saúde Pública da Escola Nacional de Saúde Pública, Rio de Janeiro, para enfermeiros, engenheiros, farmacêuticos, médicos veterinários, além dos médicos que já participavam dessa formação (Obbadi, 2010). Com isso, aparecem também as denominações, por exemplo, de enfermeiro-sanitarista e engenheirosanitarista. Em 1970, segundo Nunes (1994), ampliam-se os programas stricto sensu da Saúde Coletiva ou correlata da época, o que fortaleceu esse nível de formação para graduados de diferentes áreas.

A contar de 1990, há redução dos cursos lato sensu e, com investimento nacional, crescem os cursos de mestrado e doutorado no campo da Saúde Coletiva (Associação Brasileira de Saúde Coletiva, 2012a). Nesse período, egressos advindos da pós-graduação passam a ser chamados de gestores, epidemiologistas, professores e pesquisadores, além de começar uma fragmentação das subáreas do campo da Saúde Coletiva entre Epidemiologia, Ciências Sociais aplicadas à Saúde, Gestão e Planejamento, e Vigilância Sanitária e Epidemiológica (Campos, 2005).

Reiteramos que a formação generalista da Saúde Coletiva para o nível superior surge no início do século XXI, determinada por um saber específico oriundo do núcleo da Saúde Coletiva. Possivelmente, a formação graduada (generalista) e pós-graduada (especialista) em Saúde Coletiva, serão as credenciais para essa nova profissão da Saúde.

A regulamentação pelos órgãos oficiais é mais um dos passos para a construção de uma profissão. Atualmente, há dois projetos de lei do Senado (PLS) e um projeto de lei (PL) da Câmara dos Deputados, sobre regulamentação profissional de duas profissões, em que suas atividades se aproximam da Saúde 
Coletiva. O PL 6311/2016, na Câmara dos Deputados, em tramitação, sobre a profissão de sanitarista; o PLS 185/2014, em tramitação, e o PL 2526/2015 apensado ao PL 7482/2014, sobre a profissão de gestor de serviços de saúde (Brasil, 2014, 2015, 2016).

As atribuições descritas para o exercício profissional do sanitarista, no PL 6311/2016, estão relacionadas à Gestão de atividades de Saúde Pública e da área de Vigilância em Saúde, especialmente de Vigilância Sanitária. Os formados em curso superior da área da saúde e engenharia ou com pós-graduação em área de concentração em Saúde Pública, Engenharia Sanitária e Sanitarismo, estariam aptos para essa atuação. Já o outro PL 2526/2015 e o PLS 185/2014, facultam o exercício da profissão de gestor de serviços de saúde aos bacharéis em Gestão de Serviços de Saúde ou aos pós-graduados em Gestão de Serviços de Saúde; no teor de ambos os projetos não há menção à Graduação ou PósGraduação em Saúde Coletiva/Saúde Pública.

Percebemos que nenhum projeto de lei, em tramitação no Congresso Nacional, corresponde a todas as competências de um bacharel em Saúde Coletiva. Tais projetos apenas pincelam atividades do campo e núcleo da Saúde Coletiva e trazem uma separação entre a profissão de gestor de serviços de saúde e a de sanitarista. De fato, as atividades descritas por um são diferentes das descritas pelo outro, porém todas podem ser desenvolvidas por um único profissional generalista.

No Brasil, a regulamentação da profissão, projeto de lei aprovado no Congresso Nacional e sancionado pelo presidente da República, implica em fazer reserva de mercado de trabalho. Algumas profissões usam de conselhos profissionais para regular seu trabalho e outras não necessitam dessa forma de organização para se constituir como uma profissão.

Foi discutido no estudo de Silva (2015) que, para alguns estudantes e egressos do CGSC, o movimento de profissionalização não acarretará em reserva de mercado apenas para os sanitaristas graduados, e eles esperam dialogar com os serviços e com a pós-graduação desse campo, além de afirmarem a necessidade de amadurecimento do debate. De acordo com Paim e Pinto (2013), o que potencializaria a inserção dos sanitaristas seria a realização de concursos públicos e a criação de carreiras no setor público, compreendendo que os conselhos profissionais podem valorizar o corporativismo acima dos interesses sociais.

Corroboramos o questionamento de Freidson (1996) sobre o pressuposto de criar conselhos ou associações profissionais como necessários para o estabelecimento de uma profissão. O autor baseia-se em cada contexto histórico e cita que, na Europa, em tempos nos quais não havia associações, foram criados programas profissionais nas universidades, assim como reservas de mercado de trabalho sob a forma de cargos no serviço público para os graduandos. “Foi esse o caso também na Alemanha do século XX, quando foram criadas 
muitas daquelas que Siegrist (1990, apud Freidson, 1996, p. 150) denominou 'profissões de Estado'".

Na inserção no mundo do trabalho o desafio do reconhecimento da profissão em Saúde Coletiva interfere na empregabilidade dos bacharéis quando, por exemplo, há concursos públicos para o cargo de sanitarista incluindo apenas os pós-graduados em Saúde Coletiva, como relata o Egresso H, que foi aprovado em um desses concursos sem possuir pós-graduação na área e que, logo depois, concluiu um Curso de especialização para atender os prérequisitos do concurso antes de ser convocado para o cargo:

(...) fui olhar o edital [do concurso público] e os pré-requisitos era (sic) ser formado na área da saúde com especialização em Saúde Coletiva/Saúde Pública ou Saúde da Família. Aí eu disse: eu vou tentar só por experiência. Acabei sendo aprovada, era uma vaga, e fiquei: meu Deus, e agora! Como é que eu faço para pedir equivalência de nome do Curso? Aí entrei em uma especialização [na área de Saúde Coletiva] (...). Se eu não conseguisse concluir essa especialização, ou fosse chamada antes de concluir, como seria? Eu teria conseguido entrar [ocupar o cargo de Sanitarista]? Eu iria ter que brigar na justiça para poder conseguir equivalência? Eu não sei como seria esse processo (Depoimento de Egresso H).

Situações semelhantes ocorreram com outros egressos no estado da Bahia, como foi constatado no estudo de Anjos (2015), em que alguns concursos públicos exigiram o registro profissional no conselho de classe e o estabelecimento da carga horária mínima do curso superior, impossibilitando a inserção de egressos que apenas tivessem o bacharelado em Saúde Coletiva como única graduação.

Em uma pesquisa sobre os concursos públicos do campo da Saúde Coletiva no Brasil, no período de 2012 a 2015, foram localizados 23 editais, sendo 17 destes para o cargo de sanitarista, dois para o cargo de bacharel em Saúde Coletiva e quatro para os cargos de analista/técnico/especialista em Gestão em Saúde. Quanto aos pré-requisitos, apenas seis desses editais permitem a inclusão dos bacharéis em Saúde Coletiva, já que 13 editais são direcionados a outras graduações seguidas de especialização em Saúde Coletiva/Saúde Pública e quatro dizem ser para outras graduações da área da saúde sem exigência de especialização (Cezar et al., 2015).

Nesse sentido, o reconhecimento desse novo sanitarista para os demais profissionais e para os órgãos oficiais do Estado precisa ser alcançado, como também o reconhecimento social. Existe a necessidade de esclarecer o papel social do sanitarista, sua história e suas possibilidades de atuação (Silva, 2015), já que a imagem pública é um elemento fundamental para o sucesso de uma profissão, ainda mais para aquela que se constroi (Abbott, 1988). 
Há também aqueles que buscaram inserção no setor público através de concursos para cargos de nível médio ou técnico-administrativo, seja na área da saúde ou em outros setores, por exemplo, serviço social. No entanto, foram processos seletivos para contratos temporários de seis meses ou mais em caso de haver prorrogação.

Em outro estudo sobre a inserção profissional dos bacharéis em Saúde Coletiva da Bahia, a ocupação de profissionais de nível superior em cargos de nível médio ou fundamental foi identificada apenas no caso de um único egresso. Debate-se que essa problemática não é específica desse novo sanitarista, exemplificando a enfermagem que tem seus egressos ocupando cargos de auxiliares e técnicos (Anjos, 2015).

Em relação à subcategoria identidade profissional, problematizamos se o médico sanitarista graduado no início do século XX, os atuais sanitaristas especializados e os bacharéis em Saúde Coletiva realizariam as mesmas atividades profissionais; se sim, então eles teriam a mesma identidade?

Para Silva e Pinto (2014), a identidade, nesse caso, tem configuração 'híbrida'. As identidades profissionais mostram-se diferentes por suas formações de origem, mas todos se comportam no campo de atuação da Saúde Coletiva. Todos os profissionais sanitaristas (enfermeiro, médico, bacharel em Saúde Coletiva, odontólogos, entre outros) têm uma identidade que se diferencia dos demais profissionais, mas que pouco se diferencia entre si. A chegada dos graduados em Saúde Coletiva poderá ou não causar uma crise de identidade, ao vir fortalecer a identidade do sanitarista ou criar uma nova, um novo ser sanitarista (Silva e Pinto, 2014).

A identidade dos bacharéis ainda é desconhecida para alguns contratantes. Alguns egressos relataram que os empregadores têm preferência por contratar profissionais com conhecimento biológico por entenderem que são os mais qualificados para funções sanitárias e de gestão da Saúde Pública.

Outro aspecto comentado por alguns egressos é a respeito daqueles empregadores que associam as competências do bacharel em Saúde Coletiva a atividades técnicas/burocráticas da administração, como diz o Egresso C:

(...) [os contratantes] confundem que a Graduação em Saúde Coletiva, pelo nome de Gestão em Sistemas e Serviços de Saúde, é uma graduação voltada para questão administrativa burocrática, para elaborar planilhas, trabalhar preparando documentos, arquivamento... Eu acho que isso dificulta bastante o nosso processo de trabalho e também há uma indefinição da identidade desse profissional (...) talvez por ser uma graduação nova não compreenderam que a gente também faz planejamento, articula políticas, micropolíticas... (Depoimento de Egresso C).

Em outra sessão de GF, no entanto, alguns egressos discordam sobre a problemática apontada pelo Egresso C e afirmam que quando se esclarece 
sobre a formação do CGSC para os contratantes já há a compreensão deles sobre as diversas possibilidades de atuação desses bacharéis. O fato é que há necessidade de esclarecer e disseminar a identidade desse novo sanitarista que emerge como uma novidade para que ela seja compreendida e aceita.

No que diz respeito à subcategoria Interferência Política, a inserção, para muitos no setor público na área de formação do CGSC, dá-se por contrato temporário ou cargo comissionado por uma articulação e intermediação política. Esse cenário é visto pelos bacharéis como um trabalho instável, gerando sentimento de insegurança e medo. Esses sentimentos despertam, em alguns, a busca por profissões reconhecidas pela sociedade e por órgãos do Estado. O Egresso $\mathrm{P}$ revela suas angústias ao sair de um trabalho na sua área de formação por interferências políticas:

Um grande desafio é a pressão política. Não aguentei essa pressão, estava insatisfeito (...) e pedi para sair [da direção de uma Unidade Básica de Saúde no interior do estado]. Enquanto não pudermos ser concursados na área, vai ser bem difícil, já que existe muita interferência política (Depoimento de Egresso P).

Houve também relatos de que os posicionamentos de não atuar na área de formação do CGSC são de egressos que desde o início da graduação já sonhavam em seguir outra profissão ou eram profissionais da saúde que visualizaram o CGSC como uma 'especialização' ou não souberam o momento de esperar e procurar as oportunidades de emprego no setor saúde. Sobre esse terceiro ponto, o Egresso B relata:

A gente percebia muito um medo de se mostrar no mercado de trabalho. As pessoas não se sentiam seguras como sanitaristas (...) pelo menos na nossa turma houve muita essa insegurança (...) então parte da nossa turma acabou indo para outros caminhos, buscando outros caminhos e eu atribuo isso a essa insegurança porque o pessoal nem se mostrou. Como é que vai saber se não vai conseguir, se vai ter sucesso, se não vai ter sucesso? O pessoal nem procurou [emprego]! (Depoimento de Egresso B).

Considerando o perfil econômico dos estudantes do CGSC do Brasil, temse que $68,7 \%$ pertencem às famílias cuja renda não ultrapassa seis salários mínimos e, destes, 26,3\% apresentam renda familiar menor que três salários mínimos. Mais de 53\% trabalham e 33,6\% contribuem na renda familiar (Castellanos et al., 2013). Tais dados nos sugerem que, provavelmente, a espera por uma oportunidade de emprego, para alguns, não é uma escolha. Almejam qualquer trabalho porque precisam se sustentar financeiramente. Se o em- 
prego faz parte da área de formação do curso ou não, isso parece ser o menor dos problemas para quem busca um mínimo de estabilidade.

Sobre a interferência político-partidária, foi discutido que a inserção profissional do egresso dependerá do interesse do gestor em contratá-lo e que alguns podem aproveitar-se dos cargos públicos para obter barganha eleitoral, ou seja, negociar cargos comissionados em troca de votos e, consequentemente, não terá a preocupação de colocar profissionais qualificados para assumir cargos da área da saúde. O estudo de Silva (2015), quando debate a inserção dos bacharéis em Saúde Coletiva, identificou as mudanças político-partidárias como limitador dessa inserção.

Apesar de a interferência política ser considerada uma dificuldade, ainda é a forma como alguns egressos conseguiram sua inserção profissional. Destacamos os relatos de inserção dos Egressos I, S e T, a seguir.

O Egresso I ocupa o cargo de assessor em políticas públicas na gestão central da Secretaria Municipal de Saúde (SMS), em município da região metropolitana do Rio Grande do Norte. Sua inserção nesse espaço ocorreu logo após a conclusão do curso, no ano de 2014. Ele relata que seu cônjuge fez a articulação por conhecer políticos da cidade e a definição do cargo foi dada pelo próprio secretário de saúde ao necessitar de um profissional com conhecimentos de gestão nessa função.

Indicação política por insistência da família fez o Egresso S conseguir emprego em sua cidade, no interior do estado do Rio Grande do Norte, na gestão do nível central da SMS, após um ano de sensibilização com o prefeito. Inicialmente, o egresso foi alocado para o setor de estatística dessa secretaria, onde desenvolvia uma atividade de alimentação de dados no sistema de informação. Logo, percebeu que esse trabalho não pertencia a sua proposta de formação. Poucos meses depois, com a entrada de um novo secretário de saúde, este reconheceu que o egresso poderia contribuir mais em outra ocupação, então, em parceria, decidiram que o Egresso S assumiria o cargo de avaliador dos Serviços de Saúde.

No caso do Egresso T, foi indicação política e um pouco de conhecimento do gestor municipal sobre o curso que o levaram a conseguir seu emprego na função de secretário adjunto de Saúde Pública em uma cidade do interior do Rio Grande do Norte. Nesse espaço, os demais profissionais da saúde o veem como apenas uma indicação política, sem qualquer relação das atribuições desenvolvidas com sua formação profissional, o identificam como alguém que merece ser ouvido por certa influência política que tem na cidade. 


\section{Potencialidades para inserção profissional}

As potencialidades para a inserção profissional dos novos sanitaristas estão apresentadas nestas subcategorias: vivências práticas durante a formação; núcleo de saber e prática da Saúde Coletiva; e cenário da SMS de Natal.

Sobre as vivências práticas durante a formação, são identificadas ações que oportunizam ao graduado realizar práticas na pesquisa, no sistema e nos serviços de saúde, e possibilitam aos estudantes demonstrar aos possíveis contratantes suas qualificações profissionais.

Dentre as vivências, destacam-se os estágios curriculares do CGSC da UFRN, primeiramente, pelo conhecimento prático adquirido em Saúde Coletiva e, em segundo lugar, pela oportunidade de dar visibilidade ao curso e ao aluno para os demais profissionais no campo de estágio, já que há exemplos de contratação de egressos como consequência da convivência com seus contratantes. Destacamos a fala do Egresso F, a seguir, por exemplificar essa situação e fazer referência ao estágio como um trabalho; alguns dos egressos também usaram o verbo trabalhar ao se referir aos momentos de estágio.

Durante os estágios [curriculares] na gestão distrital conheci toda a equipe e isso foi muito interessante porque era o meu primeiro contato de trabalho (...). O gerente do Distrito gostou do meu trabalho [estágio] lá [Distrito Sanitário]. No ano seguinte à conclusão do curso, ele lembrou de mim quando estava precisando de uma pessoa para trabalhar como assessor de uma instituição filantrópica (...) aceitei o trabalho (...) (Depoimento de Egresso F).

No entanto, esse momento passa a ser considerado uma potencialidade para a inserção quando há qualidade no desenvolvimento da metodologia do Estágio Curricular, existe o comprometimento e a qualificação de preceptores e ocorre o engajamento do discente.

Segundo Pimenta (1995), o estágio deve ser um momento da formação que desenvolva nos discentes um processo de reflexão-ação-reflexão e sintetize os conteúdos, as matérias de ensino, as teorias de aprendizagem e as experiências pessoais. O processo de reflexão-ação-reflexão dito por Pimenta (1995) ocorre nessa relação entre teoria e prática quando o apreendido durante as aulas é experienciado nos campos de estágio, neste caso, há uma relação entre o núcleo de saber e a prática da Saúde Coletiva.

Sobre a subcategoria núcleo de saber e prática da Saúde Coletiva, a diversidade dos espaços de atuação foi identificada pelos egressos como potencialidade para a inserção profissional. O Egresso C exemplifica alguns desses espaços que podem ser ou que são ocupados: 
O amplo campo de atuação profissional do bacharel em Saúde Coletiva não é só na gestão, é assessoria, planejamento, educação permanente, formação docente e como pesquisador (Depoimento de Egresso C).

Ainda mais, antes da criação dos CGSC, Teixeira (2003) identificou que ao atuar no SUS esses egressos poderiam atuar no âmbito político-gerencial e no técnico-assistencial; a autora explica que os bacharéis poderiam ser responsáveis pelas:

(...) práticas de formulação de políticas, planejamento, programação, coordenação, controle e avaliação de sistemas e serviços de saúde, bem como contribuir para o fortalecimento das ações de promoção de saúde e das ações de vigilância ambiental, sanitária e epidemiológica, além de participarem de outras ações estratégicas para a consolidação do processo de mudança do modelo de atenção (Teixeira, 2003, p. 165).

A inserção e a permanência dos bacharéis em diferentes espaços poderão nos revelar a necessidade de profissionais qualificados para o núcleo de saberes e práticas da Saúde Coletiva. Com isso, os relatos dos entrevistados trazem críticas aos egressos que apenas consideram os espaços de trabalho na capital do estado como promissor. O fato é que os relatos mostraram existir um mercado no interior do estado ainda a ser explorado. Tal evidência, ainda que tenha sido pontual, poderá alertar para o fato de que a problemática das dificuldades de interiorização identificadas em algumas profissões da saúde tende a se reproduzir também, em alguma medida, para a inserção de bacharéis em Saúde Coletiva em municípios mais distantes da capital.

A próxima subcategoria que abordaremos expressa um cenário em que havia essa necessidade de profissionais com competência e habilidade para atuar na Saúde Coletiva e que, aos poucos, os demais profissionais da saúde reconheceram nos egressos do CGSC o ator responsável para suprir essa carência. Trata-se do Cenário da SMS de Natal em que há a identificação pelos egressos de que essa instituição é a maior empregadora, apesar de o vínculo empregatício ser por cargo comissionado, além de ser a que mais reconhece e compreende essa formação, principalmente por ser um dos principais campos de estágio curricular do CGSC da UFRN.

As falas mostram as potencialidades que fizeram e fazem o estudante e o egresso serem reconhecidos dentro da SMS de Natal. Consideramos o contexto favorável que a instituição vivenciou com a presença de um docente do curso como secretário municipal de saúde e de outros fatores, como o comprometimento dos alunos durante o estágio curricular; a necessidade de profissionais qualificados para atuar na gestão; e, posteriormente, a atuação profissional dos egressos. 
Identificamos que, à medida que os egressos se inserem e atuam profissionalmente na SMS, conseguem construir sua identidade profissional e serem reconhecidos pelos demais profissionais quanto à qualificação e pela contribuição para o sistema de saúde, como ilustra o depoimento do Egresso E:

Assim, eu acho que com o passar do tempo, a gente já criou uma identidade dentro da secretaria [SMS de Natal]. Que agora é "os meninos de gestão", "vamos chamar eles para participarem desse projeto para ver se leva para frente, se tem êxito". E a gente conquistou isso porque arregaçamos as mangas e trabalhamos. E a gente se destacou um pouco, por mais que a gente exerça um cargo comissionado, nós somos técnicos para assumir aquele cargo e a gente consegue dar resposta, diferente de outras pessoas (...) (Depoimento de Egresso E).

Esperamos que o exemplo do cenário da SMS seja suficiente para problematizarmos que não só os novos sanitaristas têm conseguido se inserir profissionalmente, como também permanecem no mundo do trabalho. Essa permanência, somada à acreditação dos demais profissionais na qualificação do novo sanitarista, reforça o diagnóstico de que há uma lacuna na formação das demais graduações da área da saúde para atuar na Saúde Coletiva.

\section{Estratégias para a inserção profissional}

Questionamos os egressos sobre que estratégias estariam organizando para superar os desafios de inserção. As respostas emergiram de duas maneiras, uma que caracteriza um movimento organizado e outra que destaca iniciativas individuais. O objetivo de sensibilizar gestores para contratá-los e divulgar o curso e o profissional formado aparece para os dois grupos. Conquistar a regulamentação da profissão e articular concursos públicos para o cargo de sanitaristas são objetivos específicos do grupo organizado por alguns dos estudantes e egressos do curso.

Entre as dúvidas sobre um mercado de trabalho para os novos sanitaristas, Bosi e Paim (2010) já destacaram que os estudantes e egressos do curso seriam os protagonistas nesse movimento de criação da carreira e no avanço de uma nova profissão da saúde.

O movimento articulado entre egressos e estudantes é chamado de Grupo de Trabalho (GT) de Saúde Coletiva. Este é comentado em todas as sessões dos GF como estratégia mais organizada e ativa na perspectiva de articular ações para a inserção do sanitarista graduado no SUS, como reforça o Egresso G:

Do GT aqui, eu acho que é um bom exemplo, que tem trabalhado para dar visibilidade ao Curso e tem tentado articular com professores, com gestores a questão 
da regulamentação, da inserção desse profissional em concursos [públicos] (Depoimento de Egresso G).

Os egressos descrevem ações realizadas por esse GT de Saúde Coletiva, tais como: divulgação do profissional em redes sociais; participação em congressos científicos, nos Encontros Regionais e Nacionais de Estudantes em Saúde Coletiva e em eventos internos da UFRN, como a Mostra de Profissões; e apresentação da proposta formativa do CGSC nas reuniões das Comissões Intergestores Regionais do Rio Grande do Norte.

Alguns destacaram a conquista do concurso público no município de Natal para o cargo de sanitarista como fruto da articulação entre o GT de Saúde Coletiva, professores e a coordenação desse curso.

Vale salientar que a lei complementar municipal n. 169/2017 criou por concurso público dez novos cargos para sanitarista, considerando que graduados e pós-graduados em Saúde Coletiva/Saúde Pública poderão concorrer igualmente ao cargo (Natal, 2017). Certamente, a estratégia de articulação política realizada pelo coletivo superou a necessidade de regulamentação da profissão para que esses bacharéis fossem reconhecidos como profissionais qualificados para atuar na Saúde Coletiva.

Por sua vez, no estado da Bahia, houve uma resistência dos pós-graduados em Saúde Coletiva na inclusão dos graduados no mesmo nível da carreira de sanitarista. Alguns profissionais chegaram a propor que houvesse duas carreiras de sanitaristas, uma para os sanitaristas graduados e outra para os sanitaristas especializados (Paim e Pinto, 2013).

A inserção no mundo do trabalho poderá gerar, em alguns estados da federação, embates entre sanitaristas especializados e graduados, de cunho corporativista, mas ao certo uma articulação, negociação política, poderia garantir essa inserção para ambas as formações, como no caso da cidade de Natal.

Outra estratégia de inserção que se assemelha com o GT de Saúde Coletiva mas aparece como iniciativa individual de egressos é a tentativa de influenciar uma nova cultura institucional no local de trabalho, construindo a visão de que existem sanitaristas graduados e que podem desempenhar as mesmas funções dos sanitaristas especializados, dito na fala do Egresso B adiante, e a insistência de cada egresso em sensibilizar os gestores municipais a contratá-los, principalmente no interior do estado, em que o profissional ainda não é tão conhecido nem reconhecido.

A nível de Secretaria Estadual, a gente faz uma estratégia quase que contínua de convencimento para tentar inserir esses bacharéis como profissionais a serem contratados (...). Eu sempre converso com a coordenadora do curso, nestes termos: “ah, eu preciso atuar aqui para a gente convencer, está na hora de decisão" (...) 
houve um tempo que era estágio, a gente estava nesse convencimento e inserimos estágios remunerados [para os graduandos do CGSC] que antes eram ocupados por graduandos de outros cursos (Depoimento de Egresso B).

Os egressos citaram estratégias para a inserção profissional que parecem buscar articulações político-institucionais com o apoio da coordenação do CGSC, no âmbito do estado do Rio Grande do Norte.

\section{Considerações finais}

De forma geral, os relatos dos egressos sobre a inserção profissional têm em destaque as palavras 'convite', 'indicação' e 'chamado'. Tais palavras sugerem a ocupação de cargos comissionados, contrato temporário ou por regime CLT. Consideramos que o fato de ser indicação não desqualifica o novo sanitarista, visto que alguns conquistaram essa oportunidade ao terem demonstrado aos contratantes seus potenciais durante alguma atividade, por exemplo, durante os estágios curriculares. Por outro lado, alguns egressos destacam a nomeação política como fator preponderante para sua inserção, com isso, ter qualificação para o cargo aparece como aspecto menos importante.

Esperamos que os projetos de lei, ainda em tramitação no Congresso Nacional, possam ser mais bem debatidos em suas respectivas comissões para que haja mudanças em sua estrutura, e que os debatedores percebam a necessidade social de uma nova profissão da saúde, independentemente de sua nomenclatura de sanitarista ou gestor.

Enfatizamos que a regulamentação da profissão, quando aprovada pelo Congresso Nacional, não definirá o sanitarista como uma profissão de acordo com os conceitos da sociologia das profissões, abordados neste estudo com base em Freidson (1996); para essa definição, há outros elementos, como, por exemplo, o reconhecimento social, a regulação de práticas de competição no mercado de trabalho e a definição do monopólio de saber. O movimento nacional dos novos sanitaristas impulsionará a construção de uma profissão quando articulado com outros atores sociais, por exemplo, os pós-graduados em Saúde Coletiva, o Conselho Nacional de Saúde, o Conselho Nacional de Secretários de Saúde, o Conselho Nacional de Secretários Municipais de Saúde, o MS, o MTB, a Abrasco, a Rede Unida, as instituições formadoras e outras entidades e coletivos sociais.

Ao certo, os desafios de empregabilidade identificados neste estudo também podem ser encontrados nas demais profissões, o que nos revela um contexto estrutural de desafios no mundo do trabalho. Ainda mais, destacamos que debater a necessidade social desse novo sanitarista é ir além da discussão de inserção no mundo do trabalho proposta por este artigo; por isso, sugerimos novos estudos que ampliem este debate. 


\section{Colaboradores}

As autoras participaram de todas as etapas da pesquisa e na elaboração deste artigo.

\section{Agradecimentos}

As autoras agradecem a Aline Grimberg, Averlândio Wallysson, Louise Melo, Nathanny Moutinho e Thaís Paulo, por participarem como relatores das sessões dos GF. Ainda agradecemos ao Departamento de Saúde Coletiva e ao Núcleo de Estudos em Saúde Coletiva da UFRN, pela infraestrutura disponibilizada para a realização desses GF.

Resumen Discurriremos sobre la inserción profesional de los licenciados en Salud Pública, específicamente respecto a los desafíos, potencialidades y estrategias de inserción en el mundo laboral. La producción de los datos se produjo, principalmente, a través de tres sesiones de grupo focal con los egresados de los años de 2012.2, 2013.2 y 2014.2, de la licenciatura de Salud Pública de la Universidad Federal del estado de Rio Grande do Norte. Los relatos obtenidos fueron sistematizados y sometidos a la técnica de análisis de contenido temático de Bardin. Sobre los desafíos profesionales, debatimos las subcategorías: remuneración, reconocimiento de la profesión en Salud Pública, interferencia política e identidad. En el caso de las potencialidades tenemos las siguientes subcategorías: vivencias prácticas durante la formación; núcleo de saber y práctica de la Salud Pública; y escenario de la Secretaría Municipal de Salud de la ciudad de Natal. Respecto a las estrategias para inserción profesional, identificamos acciones de carácter individual y colectivo, un movimiento organizado por egresados y estudiantes que buscan divulgar la carrera y a su profesional, así como avanzar en el proceso de construcción de una nueva profesión.

Palabras clave salud pública; mercado de trabajo; graduación en salud pública. 


\section{Notas}

${ }^{1}$ Universidade Federal do Rio Grande do Norte, Programa de Pós-Graduação em Saúde Coletiva, Natal, Rio Grande do Norte, Brasil.

$<$ lisboa.jussara@gmail.com>

Correspondência: Departamento de Saúde Coletiva, Campus Universitário, Lagoa Nova, CEP 59078-970, Natal, Rio Grande do Norte, Brasil.

${ }^{2}$ Universidade Federal do Rio Grande do Norte, Centro de Ciências da Saúde, Departamento de Saúde Coletiva, Natal, Rio Grande do Norte, Brasil.

<betcris2013@gmail.com>

${ }^{3}$ Vale destacar que atualmente esse curso não está formalmente nos principais espaços de representação nacional dos cursos que se denominam pertencentes ao campo da Saúde Coletiva, como o FGSC da Abrasco e a Coordenação Nacional de Estudantes de Saúde Coletiva.

${ }^{4}$ Este artigo resultou da dissertação de mestrado em Saúde Coletiva intitulada Sou Bacharel em Saúde Coletiva, e agora? Sobre quando novos sanitaristas entram no mundo do trabalho de autoria de Jussara Lisboa Viana, realizada na UFRN, com financiamento da Coordenação de Aperfeiçoamento de Pessoal de Nível Superior (Capes), Programa de Demanda Social, por meio de bolsa de mestrado.

${ }^{5}$ Segundo o autor, 'financeirização' representa o "crescimento assimétrico da acumulação financeira em contraponto à acumulação real, uma alteração no equilíbrio entre as duas formas de acumulação" (Mendes, 2016, p. 24). 


\section{Referências}

ABBOTT, Andrew. The system of professions: an essay on the division of expert labor. Chicago: The University of Chicago Press, 1988.

AMARAL, Alexandre S. Vamos à vacina?: doenças, saúde e práticas médico-sanitárias em Belém (1904-1911). 2006. 282 f. Dissertação (Mestrado em História Social da Amazônia) - Universidade Federal do Pará, Centro de Filosofia e Ciências Humanas, Programa de Pós-Graduação em História Social da Amazônia, Belém, 2006.

ANJOS, Davllyn S. O. Mercado de trabalho em saúde: expectativas para a inserção profissional do bacharel em Saúde Coletiva. 2015. 42 f. Dissertação (Pós-Graduação em Saúde Coletiva) - Instituto de Saúde Coletiva, Universidade Federal da Bahia, Salvador, 2015.

ASSOCIAÇÃO BRASILEIRA DE SAÚDE COLETIVA (ABRASCO). GT Trabalho e Educação. Oficina de graduação em Saúde Coletiva: mercado de Trabalho para os novos profissionais da Saúde Coletiva. Relatório final. Salvador, 2012a.

ASSOCIAÇÃO BRASILEIRA DE SAÚDE COLETIVA (ABRASCO). V REUNIÃO DO FÓRUM DE GRADUAÇÃO EM SAÚDE COLETIVA (FGSC), 5. CONGRESSO BRASILEIRO DE SAÚDE COLETIVA, 10. Porto Alegre, 2012. Relatório final. Porto Alegre: Abrasco, 2012b.

BARDIN, Laurence. Análise de conteúdo. 3. ed. Lisboa: Edições 70, 2004.

BELISÁRIO, Soraya A. et al. Implantação do curso de graduação em Saúde Coletiva: a visão dos coordenadores. Ciência \& Saúde Coletiva, Rio de Janeiro, v. 18, n. 6, p. 1.625-1.634, 2013.

BOSI, Maria L. M.; PAIM, Jairnilson S. Graduação em Saúde Coletiva: limites e possibilidades como estratégia de formação profissional. Ciência \& Saúde Coletiva, Rio de Janeiro, v. 15, n. 4, p. 2.029-2.038, 2010.
BRASIL. Presidência da República. Casa Civil. Subchefia para Assuntos Jurídicos. Decreto n. 6.096, de 24 de abril de 2007. Institui o Programa de Apoio a Planos de Reestruturação e Expansão das Universidades Federais-Reuni. 2007. Disponível em: < http://www.planalto. gov.br/ccivil_03/_ato2007-2010/2007/decreto/ d6096.htm>. Acesso em: 10 nov. 2016.

BRASIL. Senado Federal. Projeto de lei do Senado 185, de 2014. Dispõe sobre o exercício da profissão de Gestor de Serviços de Saúde e dá outras providências. 2014. Disponível em: <http://www25.senado.leg.br/web/atividade/materias/-/materia/117790 > . Acesso em: 20 fev. 2017.

BRASIL. Câmara dos Deputados. Projeto de lei 2.526, de 2015. Regulamenta a profissão de Gestor de Serviços de Saúde. Situação: Apensado ao PL 7.482, de 2014, que dispõe sobre o reconhecimento da profissão de gestor de serviços de saúde. 2015. Disponível em: <http://www.camara.gov.br/proposicoesWeb/ fichadetramitacao $?$ idProposicao $=1598384>$. Acesso em: 20 fev. 2017.

BRASIL. Câmara dos Deputados. Projeto de lei 6.311, de 2016. Dispõe sobre a regulamentação da profissão de sanitarista e técnico sanitarista. 2016. Disponível em: <http://www.camara.gov. br/proposicoesWeb/fichadetramitacao?idProp osicao $=2114355$ > . Acesso em: 20 fev. 2017.

BRASIL. Conselho Nacional de Educação. Câmara Executiva. Câmara de Educação Superior. Aprovação das Diretrizes Curriculares Nacionais do Curso de Graduação em Saúde Coletiva. Diário Oficial da União, Brasília, DF, Seção 1, n. 153, p. 26, 10 ago. 2017a. Disponível em: <http://pesquisa.in.gov.br/imprensa/jsp/ visualiza/index.jsp?jornal $=1 \&$ pagina $=26 \& d$ ata $=10 / 08 / 2017>$. Acesso em: 15 nov. 2017.

BRASIL. Presidência da República. Casa Civil. Subchefia para Assuntos Jurídicos. Lei n. 13.429, de 31 de março de 2017. Altera 
dispositivos da lei n. 6.019, de 3 de janeiro de 1974, que dispõe sobre o trabalho temporário nas empresas urbanas e dá outras providências; e dispõe sobre as relações de trabalho na empresa de prestação de serviços a terceiros. Diário Oficial da União, Brasília, DF, Seção 1, Edição Extra, n. 63-A, p. 1, 31 mar. 2017b.

BRASIL. Lei n. 13.467, de 13 de julho de 2017. Altera a Consolidação das Leis do Trabalho (CLT), aprovada pelo decreto-lei n. 5.452, de $1^{\circ}$ de maio de 1943, e as leis n. 6.019, de 3 de janeiro de 1974, 8.036, de 11 de maio de 1990, e 8.212, de 24 de julho de 1991, a fim de adequar a legislação às novas relações de trabalho. Diário Oficial da União, Brasília, DF, Seção 1, n. 134, p.1, 14 jul. 2017c.

BRASIL. Ministério do Trabalho. Portal da classificação brasileira de ocupações. $2017 \mathrm{~d}$. Disponível em: <http://www.mtecbo.gov. br/cbosite/pages/home.jsf $>$. Acesso em: 16 jun. 2017.

CAMPOS, Gastão W. S. Saúde pública e saúde coletiva: campo e núcleo de saberes e práticas. Ciência \& Saúde Coletiva, Rio de Janeiro, v. 5, n. 2, p. 219-230, 2000.

CAMPOS, Gastão W. S. Romance de formação de um sanitarista: um estudo de caso. In: LIMA, Nísia T. (org.). Saúde e democracia: história e perspectivas do SUS. Rio de Janeiro: Editora Fiocruz, 2005. p. 121-150.

CASTELlAnOS, Marcelo E. P. et al. Estudantes de graduação em saúde coletiva: perfil sociodemográfico e motivações. Ciência \& saúde coletiva, Rio de Janeiro, v. 18, n. 6, p.1657-1666, 2013.

CECCIM, Ricardo B. Inovação na preparação de profissionais de saúde e a novidade da graduação em saúde coletiva. Boletim da Saúde, Rio Grande do Sul, v. 16, n. 1, p. 9-36, 2002.

CEZAR, Diego M. et al. O Bacharel em saúde coletiva e o mundo do trabalho: uma análise sobre editais para concursos públicos no âmbito do Sistema Único de Saúde. Saúde em Redes, Editora Rede Unida, Porto Alegre, v. 1, n. 4, p. 65-73, 2015.

FREIDSON, Eliot. Para uma análise comparada das profissões: a institucionalização do discurso e do conhecimento formais. Revista Brasileira de Ciências Sociais, São Paulo, v. 11, n. 31, p. 141-145, 1996.

HAMMERSLEY, Martyn; ATKINSON, Paul. Etnografia: métodos de investigación. Barcelona: Paido, 1994.

KOIFMAN, Lilian; GOMES, Lina N. A graduação em Saúde Coletiva: um debate ou uma realidade?. Revista Brasileira de Educação Médica, Brasília, v. 32, n. 4, p. 417-418, 2008.

LABRA, Maria E. O movimento sanitarista nos anos 20: da conexão sanitária internacional à especialização em saúde pública no Brasil. 1985. 408f. Dissertação (Mestrado em Administração Pública) - Escola Brasileira de Administração Pública, Rio de Janeiro, 1985.

LORENA, Allan G. et al. Graduação em Saúde Coletiva no Brasil: onde estão atuando os egressos dessa formação?. Saúde e Sociedade, São Paulo, v. 25, n. 2, p. 369-380, 2016.

MERHY, Emerson E. A saúde pública como política: um estudo de formuladores de políticas. 4. ed. São Paulo: Hucitec, 1992.

MERHY, Emerson E. O conhecer militante do sujeito implicado: o desafio em reconhecê-lo como saber válido. In: FRANCO, Túlio B. et al. (org.). Acolher Chapecó: uma experiência de mudança do modelo assistencial, com base no processo de trabalho. São Paulo: Hucitec, 2004. p. 21-45.

MENDES, Áquilas. Os impasses dos direitos sociais trabalhistas e do financiamento da seguridade social e da saúde brasileira no capitalismo contemporâneo em crise. In: SOUZA, Helton S.; MENDES, Áquilas (orgs.). Trabalho e saúde no capitalismo contemporâneo: 
enfermagem em foco. Rio de Janeiro: DOC Content, 2016. p. 15-41. Capítulo 1.

MENESES, Jéssica J. S. et al. Panorama dos cursos de graduação em Saúde Coletiva no Brasil entre 2008 e 2014. Trabalho, Educação e Saúde, Rio de Janeiro, v. 15, n. 2, p. 501518, ago. 2017.

MINAYO, Maria C. S.; GUERREIRO, Iara C. Z. Reflexividade como éthos da pesquisa qualitativa. Ciência \& Saúde Coletiva, Rio de Janeiro, v. 19, n. 4, p. 1.103-1.112, 2014.

NATAL. Prefeitura Municipal. Lei complementar n. 169, de 6 de novembro 2017. Ficam criados os cargos e ampliadas as vagas de provimento efetivo da lei complementar $\mathrm{n}$. 120, de 3 de dezembro de 2010, que integrarão o Anexo II, do Plano de Cargos, Carreira e Vencimentos dos Profissionais da Área da Saúde da SMS, e amplia as vagas de cargos de provimento efetivo que integrarão o Anexo III da lei complementar n. 118, de 3 de dezembro de 2010, do Plano de Cargos e Vencimentos dos Funcionários da Administração Direta e Autárquica da Prefeitura Municipal de Natal, respectivamente, e dá outras providências. Diário Oficial do Município, Natal, n. 3.674, p. 1, 8 nov. 2017. Disponível em: <http:// www.natal.rn.gov.br/dom/>. Acesso em: 17 nov. 2017.

NUNES, Everardo D. Saúde Coletiva: história de uma ideia e de um conceito. Saúde e Sociedade, São Paulo, v. 3, n. 2, p. 5-21, 1994.

OBBADI, Monireh. Trajetória do curso de especialização em Saúde Pública da Escola Nacional de Saúde Pública: Fiocruz - um estudo de caso. Rio de Janeiro: Editora Fiocruz, 2010. 190 f.

PAIM, Jairnilson S.; PINTO, Isabela C. M. Graduação em Saúde Coletiva: conquistas e passos para além do sanitarismo. Tempus, Brasília, v. 7, n. 3, p. 13-35, 2013.
PIMENTA, Selma G. O estágio na formação de professores: unidade teoria e prática?. Caderno de Pesquisa, São Paulo, n. 94, p. 58-73, 1995.

RUELA, Helifrancis C. G. A formação de sanitaristas e os cursos de graduação em Saúde Coletiva no Brasil. 2013. 134f. Dissertação (Mestrado Profissional em Educação Profissional em Saúde) - Escola Politécnica de Saúde Joaquim Venâncio, Fundação Oswaldo Cruz, Rio de Janeiro, 2013.

SANTOS, Liliana. Educação e trabalho na Saúde Coletiva brasileira: estudo de caso sobre a criação dos cursos de graduação na área de Saúde Coletiva nos cenários nacional e local. 2014. 201f. Tese (Doutorado em Saúde Coletiva) - Instituto de Saúde Coletiva, Universidade Federal da Bahia, Salvador, 2014.

SILVA, Vinício O.; PINTO, Isabela C. M. O sanitarista como trabalhador da saúde no Brasil: uma identidade em transformação. In: MARTINS, Maria I. C. et al. (orgs.). Trabalho em saúde, desigualdades e políticas públicas. Rio de Janeiro: Escola Nacional de Saúde Pública Sergio Arouca; Fiocruz; Portugal: Centro de Investigação em Ciências Sociais (CICS-UM), Universidade do Minho, 2014. p. 159-165.)

SILVA, Vinício O. Identidade do "sanitarista" no Brasil: um estudo sobre as concepções das lideranças estudantis dos cursos de graduações em Saúde Pública/Coletiva. 2015. 77f. Dissertação (Mestrado em Saúde Coletiva) - Instituto de Saúde Coletiva, Universidade Federal da Bahia, Salvador, 2015.

SOUZA, Elizabethe C. F. Grupos Focais. In: SOUZA, Evânia L. et al. Metodologia da pesquisa: aplicabilidade em trabalhos científicos na área da saúde. Natal: EDUFRN, 2017. p. 144-157. (No prelo)

TEIXEIRA, Carmen F. Graduação em Saúde Coletiva: antecipando a formação do Sanitarista. 
Interface: Comunicação, Saúde e Educação, Botucatu, v. 7, n.13, p. 163-6, 2003.

VIANA, Jussara L. Sou bacharel em Saúde Coletiva, e agora? Sobre quando novos sanitaristas entram no mundo do trabalho. 2017. 184f. Dissertação (Mestrado em Saúde Cole- tiva) - Pós-Graduação em Saúde Coletiva, Universidade Federal do Rio Grande do Norte, Natal, 2017.

Recebido em 11/07/2017.

Aprovado em 16/12/2017. 